\title{
Editorial
}

\section{Indigenous Chinese Management Research: Like It or Not, We Need It}

\author{
Kwok Leung \\ City University of Hong Kong, Hong Kong
}

\section{INDIGENOUS MANAGEMENT RESEARCH}

What is the most fruitful approach to developing Chinese management research is perhaps the single most important question that Management and Orgamization Revieve is set up to address. A complex question such as this one typically engenders diverse views, and there has been an ongoing debate about the best way forward. The crux of the debate centers on whether it is more productive to focus on universal or China-specific (indigenous) management theories (e.g. Barney \& Zhang, 2009; Cheng, Wang, \& Huang, 2009). The indigenous approach requires the adoption of Chinese perspectives in conceptualizing research problems and formulating theories (for detail, see Li, Leung, Chen, \& Luo, 2012).

There is a constant plea for attention to context in management research, and we should also put this debate in context. The U.S. has been the dominant economic power after World War II as well as the dominant source of management research and theories. Despite the monumental work of Hofstede (1980) on cultural dimensions, most researchers do not worry about whether research and theories coming out of the U.S. context would generalize to other cultural contexts. There has not been any significant trend to require research and theories developed in the U.S. context to take into account their relevance and applicability in other cultural contexts. In contrast, indigenous research and theories developed in the Chinese context typically generate a knee-jerk reaction about their potential lack of generalizability to other cultural contexts. As an illustration, papers based on U.S. data typically do not carry a disclaimer about their potential lack of generalizabiliy to other cultural contexts, whereas papers based on Chinese data usually include a caveat about the uncertainty of cultural generality. This difference can easily be explained by economic power. If a theory or a set of findings works in the U.S., it is 
likely to work reasonably well in Western Europe, which is pretty much what matters in economic terms. Whether or not it works, say, in Africa, does not matter in terms of real-world significance because Africa's share of the world economy is small. This lukewarm attitude is obvious in published articles: How often are findings and theories originated in the U.S. replicated and tested in Africa? How many researchers are concerned that a certain theory does not work in the African context?

The analysis based on economic power also sheds light on why Chinese management research, including context-sensitive research, often assumes a Western perspective (Tsui, 2007, 2009). Foreign direct investments have been a major driving force of the economic growth of China. For strategic reasons, many Western firms need to operate in China, the factory of the world and an increasingly important market. To succeed in managing such operations, knowledge about the Chinese context and Chinese employees is important. Demand for such knowledge explains why a large chunk of Chinese management research oricnts toward offering insight for Western firms to operate in China (e.g. Kim \& Wright, 2011; Leung, Zhu, \& Ge, 2009; Li, Chen, \& Shapiro, 2010; Wang \& Takeuchi, 2007). This type of research is typically not indigenous in orientation, because Western theories are applied, although adaptation is often made to improve their local relevance and applicability.

The economic context of the world is changing quickly. The four BRIC Countries will ascend rapidly in their share of the world economy. PricewaterhouseCoopers even predicts that China will overtake the U.S. as the largest economy in the World by 2020 (Kennedy, 2010, Jan. 21). The outward direct foreign investment of China is in the take-off stage (Alon, Child, Li, \& McIntyre, 201 1; Lu, Liu, \& Wang, 201 1; Yiu, 2011), and Chinese firms will be a major player in the global arena in a decade or two. In an era where Chinese firms are at least as important as U.S. firms, whether Chinese findings and theories are generalizable to other cultural contexts will be less crucial. Indigenous knowledge about Chinese management will be essential in the real world, and few can afford to ignore Chinese firms as much as we cannot ignore American firms today. In a nutshell, given the trajectory of the Chinese economy, we are entering an era in which indigenous Chinese findings and theories, regardless of whether they are culture-general or not, are important in their own right.

There is a second reason why indigenous Chinese findings and theories are important. Indigenous Chinese management research can offer new insight and contribute to the development of truly universal theories (Leung, 2009). For instance, a comparison of creativity across the East and West can reveal omissions in Western creativity research, and findings and theorizing originating from the East may point to intriguing and novel research directions (De Dreu, 2010; Morris \& Leung, 2010). I may add that a study in an economically unimportant country may offer unique insight for theory development because of certain specific features of the context. In general, the synthesis of indigenous research from diverse cultural contexts is perhaps the best way to arrive at truly universalistic theories (Yang, 2000). 
I believe that Chinese management research from an indigenous perspective will be taken seriously with the ascendance of the economic power of China. A key mission of $M O R$ is to promote Chinese management research, and my personal view is that we need to encourage research that is original and trail-blazing. Showing that a Western theory needs modification to work well in China is a good contribution; showing the superiority of an indigenous theory over a Western theory, even adapted for the Chinese context, is an eye-opening, stronger contribution. A spectacular and high-impact contribution, I believe, is to demonstrate that an indigenous theory can eventually be developed into a universal theory. MOR has published many papers of the first type, and some of the second type as well, such as the discussions of Chinese guanxi (e.g. Li, Yao, Sue-Chan, \& Xi, 2011; Luo, 2011) and Chinese capitalism (Fligstein \& Zhang, 201 1; Lin, 2011). I hope we will see more papers of types 2 and 3 within its pages. To further promote this goal, it is timely for MOR to publish this special issue on 'Indigenous Management Research in China', which brings clarity to what is entailed in an indigenous approach and how to conduct this type of research. Van de Ven and Jing (2012) offer an insightful commentary on indigenous management research in China from an engaged scholarship perspective, which broadens the conceptual realm of this type of research.

\section{THIS SPECIAL ISSUE}

The special issue includes an introduction by the guest editors, four articles that cover diverse topics, and a commentary. In addition, there are three regular articles, which coincidentally complement the articles in the special issue very well. Two articles are about China, with one on guanxi (Luo, Huang, \& Wang, 2012), and the other one on a review of the theoretical contributions of research conducted in the Chinese context (Jia, You, \& Du, 2012). The final article in this issue reviews the tension between indigenous vs. imported management research in Brazil (Rodrigues, Duarte, \& Carrieri, 2012), thus providing a contrast to the status of indigenous research in the Chinese context.

I congratulate all the authors in this issue for their supreme jobs in showcasing the importance and utility of the indigenous approach. This issue fulfils a core mission of $M O R$ and represents a key milestone in the development of indigenous management research. The papers as a collective will provide the much needed impetus for leapfrogging this line of research to a new height.

\section{WELCOME TO NEW MEMBERS OF THE MOR EDITORIAL TEAM}

Finally, I would like to welcome Tony Fang of Stockholm University to be the Artwork Coordinator of MOR. Research is primarily an intellectual endeavor, but delight and inspiration invoked by mesmerizing images may bring insight beyond 
what our intellect can offer. Tony will not only elevate our widely acclaimed tradition of gracing the cover of MOR with artistic photographs, but will also liven up the blank pages with beautiful images. I would also like to welcome the incoming Consulting Editors, Bor-Shiuan Cheng, Simon S. K. Lam, Kenneth S. Law, Christopher Marquis, Seung Ho Park, and Heli Wang, and Editorial Review Board Members, Xu Huang, Yi Jiang, Tae-Yeol Kim, Leigh Anne Liu, Klaus Meyer, Run Ren, Margaret Shaffer, and Song Yang, whose significant expertise will help take MOR to the next level. We are also pleased to have Eric Tsang advance from Consulting to Senior Editor. Last but not least, I extend my deep gratitude to the outgoing editors, including Ingmar Bjorkman, Xiao-Ping Chen, and Patrick Wright. They have contributed so much to the success of MOR, and I wish them the best of luck in their future endeavors.

\section{REFERENGES}

Alon, I., Child, J., Li, S., \& McIntyre, J. R. 2011. Globalization of Chinese firms: Theoretical universalism or particularism. Management and Organization Reviez, 7(2): 191200.

Barney, J. B., \& Zhang, S. 2009. The future of Chinese management research: A theory of Chinese management versus A Chinese theory of management. Management and Organization Review, 5(1): 15-28.

Cheng, B.-S., Wang, A.-C., \& Huang, M.-P. 2009. The road more popular versus the road less travelled: An 'insider's' perspective of advancing Chinese management research. Management and Organization Revieze, 5(1): 91-105.

De Dreu, C. K. W. 2010. Human creativity: Reflections on the role of culture. Management and Organization Review, 6(3): 437-446.

Fligstein, N., \& Zhang, J. 2011. A new agenda for research on the trajectory of Chinese capitalism. Management and Organization Revieze, 7(1): 39-62.

Hofstede, G. 1980. Culture's consequences: International differences in zerk-related values. Beverly Hills, CA: Sage.

Jia, L., You, S., \& Du, Y. 2012. Chinese context and theoretical contributions to management and organization research: A three-decade review. Management and Organization Revieze, $8(1): 173-209$.

Kennedy, S. 2010. Jan. 21. G-7 will be eclipsed by E-7 by 2020 as China surges, PwC says. Bloomberg. [Last accessed 25 January 2012.] Available from URL: http://www. bloomberg.com/apps/news?pid=newsarchive\&sid=awJGPSXwf4DE

Kim, S., \& Wright, P. M. 2011. Putting strategic human resource management in context: A contextualized model of high commitment work systems and its implications in China. Management and Organization Revieze, 7(1): 153-174.

Leung, K. 2009. Never the twain shall meet? Integrating Chinese and Western management research. Management and Organization Review, 5(1): 12l-129.

Leung, K., Zhu, Y., \& Ge, C. 2009. Compensation disparity between locals and expatriates: Moderating the effects of perceived injustice in foreign multinationals in China. Journal of World Business, 44(1): 85-93.

Li, J., Chen, D., \& Shapiro, D. M. 2010. Product innovations in emerging cconomies: The role of forcign knowledge access channels and internal efforts in Chinese firms. Management and Organization Review, 6(2): 243-266.

Li, P. P., Leung, K., Chen, C. C., \& Luo, J.-D. 2012. Indigenous research on Chinese management: What and how. Management and Organization Revieze, 8(1): 7-24.

Li, S. X., Yao, X., Sue-Chan, C., \& Xi, Y. 2011. Where do social ties come from: Institutional framework and governmental tie distribution among Chinese managers. Management and Organization Review, 7(1): 97-124. 
Lin, N. 2011. Capitalism in China: A centrally managed capitalism (CMG) and its future. Management and Organization Revieze, 7(1): 63-96.

Lu, J., Liu, X., \& Wang, H. 2011. Motives for outward FDI of Chinese private firms: Firm resources, industry dynamics, and government policies. Management and Organization Revieze, $7(2): 223-248$.

Luo, J.-D. 2011. Guanxi revisited: An exploratory study of familiar ties in a Chinese workplace. Management and Organization Revieze, 7(2): 329-351.

Luo, Y., Huang, Y., \& Wang, S. L. 2012. Guanxi and organizational performance: A meta-analysis. Management and Organization Review, 8(1): 139-172.

Morris, M. W., \& Leung, K. 2010. Creativity cast and west: Perspectives and parallels. Management and Organization Reviere, 6(3): 313-327.

Rodrigues, S. B., Duarte, R. G., \& Carrieri, A. P. 2012. Indigenous or imported knowledge in Brazilian management studies: A quest for legitimacy? Management and Organization Revieze, 8(1): 211-232.

Tsui, A. S. 2007. From homogenization to pluralism: International management research in the Academy and beyond. Academy of Management Joumal, 50(6): 1353-1364.

Tsui, A. S. 2009. Editor's introduction - autonomy of inquiry: Shaping the future of emerging scientific communitics. Management and Organization Revieze, 5(1): 1-14.

Van de Ven, A. H., \& Jing, R. 2012. Indigenous management research in China from an engaged scholarship perspective. Management and Organization Revieze, 8(1): 123-137.

Wang, M., \& Takcuchi, R. 2007. The rolc of goal orientation during expatriation: A cross-sectional and longitudinal investigation. Journal of Applied Psychology, 92(5): 1437-1445.

Yang, K.-S. 2000. Monocultural and cross-cultural indigenous approaches: The royal road to the development of a balanced global psychology. Asian Joumal of Social Psychology, 3: $241-263$

Yiu, D. W. 2011. Multinational advantages of Chinese business groups: A theoretical exploration. Management and Organization Revieze, 7(2): 249-277. 